\title{
Application of Remote Sensing Techniques in Land Use Pattern Auditing of Ero Dam Catchment's Basin
}

\author{
Adeniji Olawale Aladelokun (Ph.D) \\ Department of Geography, College of Education,Ikere-Ekiti,Ekiti State, Nigeria.
}

\begin{abstract}
There are many situations in which a better data base would improve our ability to audit changes that occur in our environment as a result of human interference. This is important especially when changes is extensive and numerous that their cumulative efforts can produce unforeseen results. Consequently, to have adequate appraisal of land use changes that occur at Ero Dam catchment's basin and to be able to prepare for or modify its diverse moods, remote sensing technique is employed. This involves the examination of physiographic map of 1983 and standard satellite images of Landsat MSS of 2003. The data were processed, enhanced and classified using Maximum Likelihood Classification System. The 4-Quadrant Pixel method of ground-truth and observation was utilized to determine the accuracy of the work. Therefore, map-to-map comparison was carried out using 1983 as a master to detect changes in the classified land use type in the area. The results were presented in maps and tables. In an overview from 1983-2003, the result show that agricultural land witness a reduction of size while water bodies witness a considerable increase of size. Other areas that witness increase are the built-up land, rangeland, wetland and barren land while forestland in addition to the agricultural land witnesses a decrease in size. It is obvious from the result that remote sensing technique is capable of monitoring land use changes that occur over time within a dam catchment's basin, especially when complimented with adequate ground-truth observation.
\end{abstract}

\section{Introduction}

Water is the most vital resource for life. In our planet, approximately $97.2 \%$ water lies in oceans as salt water, while $2.15 \%$ in frozen ice form and the remaining $0.65 \%$ remains as fresh water either on surface or as a ground water (Santra, 2011). The demand for fresh water has increased day by day and will increase with the rapid growth of population, agriculture and industry. As a result the fresh water reserve depletes day by day too. The requirement of clean water per person is about 2.7 litres per day, thus the global requirement is about 16.5 billion litres per day only for drinking purpose. Agriculture and industries are also major consumers of fresh water resources. Resulting from the shortage of fresh water, therefore, the call for water management science.

Water management projects have a long history as their desirability was recognized even in the early civilization especially in regions of insufficient rainfall (Adams, 1995). According to Garbrecht (1983) such great civilizations as those in the valley of the Nile, the Tigris and Euphrates, the Indus and Hong-ho were able to develop on the basic of complex and advanced water management systems. It is possible by such means as "Advanced water management system "for many to ensure adequate supply of water in time and in space which will result in meaningful improvement of the quality life for community hitherto trapped in poverty and misery brought about by lack of water. (Odihi, 1991).

In an attempt to solving this but great problem of inadequate fresh water supply, construction of Dams is one of the efforts advanced by the Nigerian government under the able supervision of various agents like water cooperation at both federal and state levels. This by the word of Rufai (1991) has had both positive and negative consequences in the area where such dam projects are located. Ero Dam in Moba Local Government area of Ekiti state, Nigeria is one out of many examples of such a water resource management scheme.

However, the nature of Dams and their impact depends on both natural and human made conditions in the project area. Socio-economic development and the installation of Dam protection measures have political, economic and social dimensions as well as engineering aspects. Empirical analysis of Dam must be of great concern and a thing to embrace as this will provide a sound technical basis for facilities design as well as for management decision making that must weight numerous other factors.

Meanwhile, there are many situations in which a better data base would improve our ability to audit our resources, make use of them, and understand our environment, and so on. Again, when changes are so rapid, so extensive, and so numerous that their cumulative effort can produce unforeseen results, the kind of monitoring which have served in the past will no longer surface. Therefore qualities and types of information here are unimagined. To have adequate appraisal of our resources in which to base plans for more ordered use, to be able to foresee incipient problems soon enough to make remedied action worth while, and to understand the natural 
environment well enough to be able to prepare for or modify its diverse moods, our ability to collect information need to be involved. However, remote sensing offers the way out.

Remote sensing according to Okhimanhe (1999) is a set of techniques (aerial photography and satellite imagery) used for obtaining information about the environment (earth surface and atmosphere) at some distance from them, usually by means of sensors which detect and record through electromagnetic of a place without necessarily having contact with such place. This implies collecting (e.g images with sensors from airborne or satellite platform, processing and analyzing the data and converting the data to useful information.

The aim of remote sensing is to produce information which can be applied in decision making or problem solving. The primary objective, therefore, is to obtain environmental resources data relate to the earth in order to enhance our knowledge of the earth surface made up of lithosphere, biosphere, hydrosphere and atmosphere, the utilization of the acquired knowledge for the benefit of humanity as well as sustainable development, the recognition and identification of varied developmental and comprehensive information for feasibility studies and project planning. (Lo, 1987 and Igbokwe, 1996).

\section{Remote Sensing And Impact Assessment}

There is extensive literature on the potentials of utilization satellite remote sensing on impact assessment, but there are few examples where satellite data have actually been used to detect different parameters at an operational scale for practical application. In this study, however, effort is geared towards the review of several 'precision' studies in which remote sensing data have been used. The focus is on possibilities and limitation in the identification for agricultural development and fish farming.

Downwan (1987) has shown the information capability of SPOT (System Probatoire del' Observation de la Terre). Literarily, meaning the Earth Observation Test System. Ononiwu (1989) supported the view. SPOT is yet incapable of use of mapping stream channel contours which allows estimate of stream channel depth and slope. However, with a combination of Digital Elevation Model (DEM) which is extracted from the SPOT Imagery, a quantitative and to some extent quantitative estimate could be made both of depth, slope and channel widths. All these are always put into consideration in dam design.

Igbokwe (1996) noted that inventorying of our surface water in the River Basin in one of the easiest applications of satellite products. Water and are not subject to serious geometrical deformation due to instability of image capture platform. This view is corroborated by Rango (1983).

Quantitative estimates of surface flows using Landsat have been discussed by Estees, et. al. (1980). The use of Landsat for monitoring lake fluctuation and thereby calculating the capacity of the lake at any instant of image capture has been discussed with reference to Qommplaya (West Central Iran) as well as lake fluctuation in the Shiraz sand Neris play as of Iran by Ononiwu (1987). These have provided useful data for the assessment and management of the water in their basin on real time basin. Different spectral values which water in some basin have exhibited most especially in the lake systems have suggested the calibration of spectral categories on the false colours composite for monitoring and assessing water quality. Ononiwu (1989) while analyzing supervised classification of Lohja Lake suggested such possibility. How far this can go beyond physical analysis has been a subject of debate.

Lillesand and Kiefer (1994) emphasized it's shortcomings to the physical aspect of water resources monitoring and potentials assessment and maintained that the remote sensing applications are limited to those characteristics that can be detected in the visible and near infrared region of the spectrum. Water quality indicators such as color, turbidity, chlorophyll and suspended solids have been successfully detected in many applications. Rango (1983) has developed a good model for estimating soil erosion through remote sensing application.

Epp, et. al (1983) were able to produce land capability map, forest cover map, wood assessment maps and habitant map for Kenya using remote sensing techniques. Adeniyi (1988) assessed the capability of hands at MSS for identifying, classifying and monitoring the impact of dam construction in the Sokoto - Rima Basin. Land use and land cover types were identified, classified using maximum likelihood procedure and the standard visual interpretation techniques to investigate the changes in dam site areas. He found that Landsat MSS was suitable for rapid classification, assessment and monitoring of the agricultural resources of the combined use of digital and visual analysis of a higher resolution data such as SPOT image would provide a baseline data for detailed agricultural resources planning and management.

Again, the work of Adeniyi and Omojola (1999) demonstrated the application of multi-source archival remote sensing and GIS data for the mapping and evaluation of land use and land cover changes within Sokoto Rima basin of northern Nigeria. The post-dam period witnessed a total of 7596.2 ha $(23.5 \%)$ changes in the land use and cover classes with evidence of large-scale conversion of agricultural lands to semi-arid environment. Land degradation resulting from land use/land cover changes of the area was equally mapped. A total of 1042.7 ha (3.2\%) of the study area was identified as areas with erosion and over grazing problem; 118.6 ha of land was under land exposure /desiccation while 791.9 ha constitute area with loss of prime (flood plain) agriculture. 
The possibility to separate vegetation communities in semi-arid area from satellite data (SPOT) has been shown to depend mainly on the difference in plant morphology and seasonal changes (Franklin and Hienaux, 1993). They asserted that, if a plant is subjected to some form of stress that interrupts its normal growth; it may decrease or cease chlorophyll production. The result will be less chlorophyll absorption in the blue and red wavelengths. In case of soil, high organic content or iron oxide in soils decrease reflectance and the soil appears darker (Larsson and Stronquist, 1991). This is because the factors that influence soil reflectance act over specific spectral bands. (Lillesand Kieffer, 1994). According to Charles and Mallo (2007) mapping of areas affected by oil spills using remote sensing and GIS techniques is an improved method of monitoring environmental problems.

Finally, all studies have established the fact that no remote sensing studies, especially those that involve forest application can be successfully and effectively carried out without thorough ground truth exercise as it is necessary to avoid spectral noise and confusion.

\section{Aim and Objectives.}

The major thrust of this study is to investigate the impact of Ero Dam on the land use pattern of the area using remote sensing techniques. The study therefore set to:

i. examine the enlargement of Ero Dam and reservoir;

ii. Identify the land use changes in the area; and

iiiTo advance recommendations based on the findings.

\section{Research Hypothesis}

This research is based on the following hypothesis as they form the basis of discussion of findings.

Ho: 1 . there is no significant difference between pre-dam and post-dam land use pattern in the study area.

Ho: 2. remote sensing is capable of detecting pre-dam and post dam changes in dam catchments basin.

\section{Methodology}

In the pursuance of the aim and objectives of this study, the data for the study were obtained mainly through secondary sources. Ground-truth of the area to determine the land use types was carried out to confirm observed ones on the satellite imageries of the study area. Personal discussion with government functionaries and prominent leaders of thought in the eight selected communities within the study area was conducted for on the spot assessment of the physical changes caused by the dam construction.

The secondary data involved are written and printed materials that have already been in existence which were produced for other purposes other than the use of the investigation for the study, some of the relevant information acquired include.

i. 1966 Physiographic map of the study Area Ado-Ekiti sheet 244 NW by Federal Ministry of Survey in Nigeria, reprinted in 1981 on a scale of 1:50.000 covering the entire catchment's area (see Fig.1)

ii. Standard Satellite Image of LANDSAT MSS, sheet $244 \mathrm{NN}$ acquired in 2003. This facilitates the assessment of the changes in land use type of the study area. (see Fig. 2)

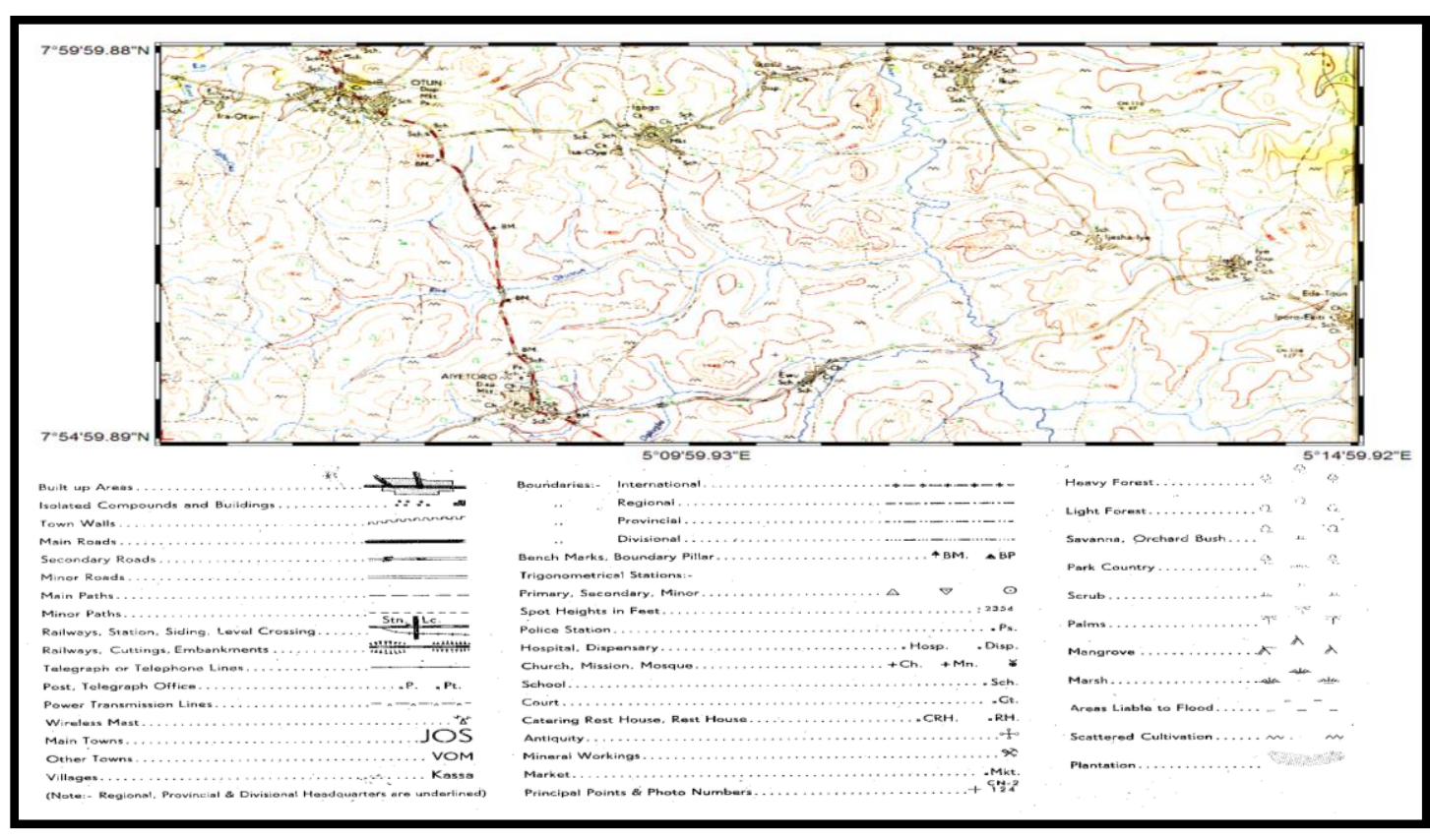



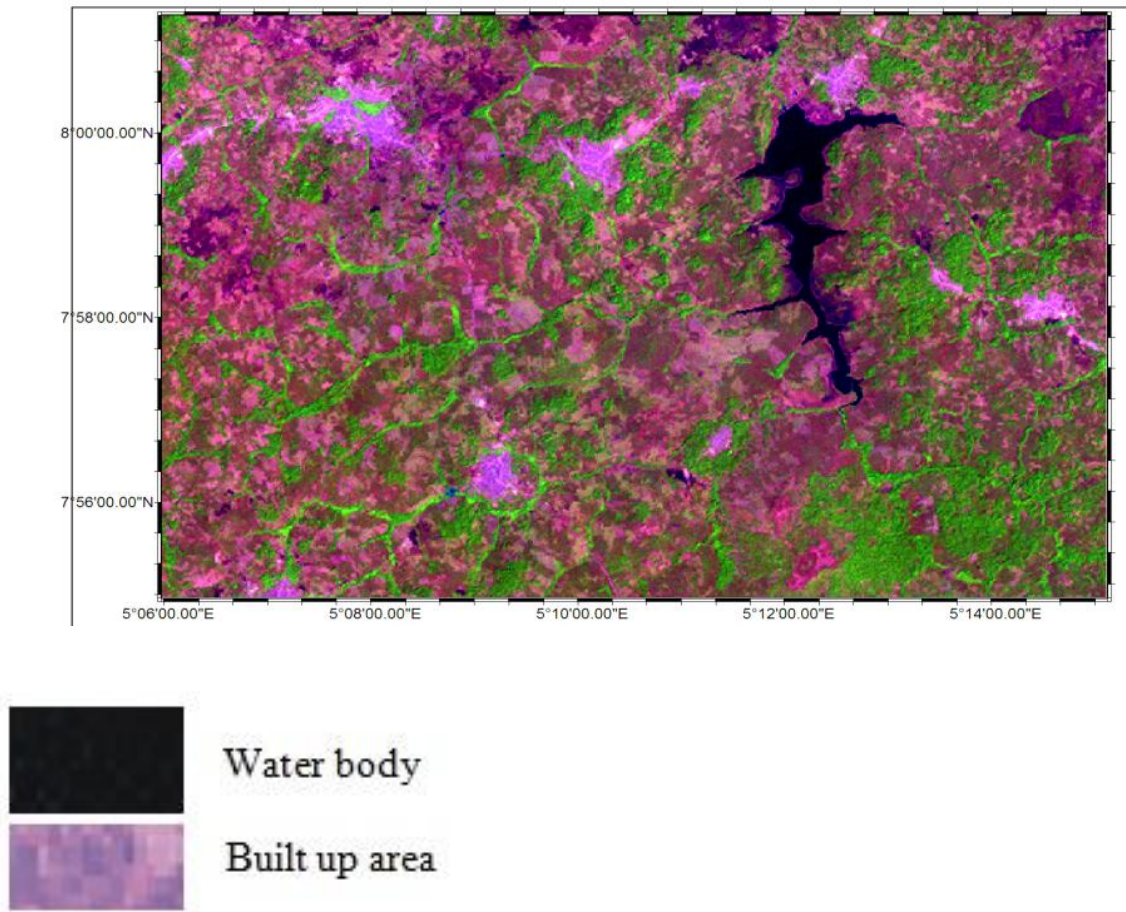

Water body

Built up area

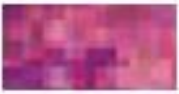

Vegetation

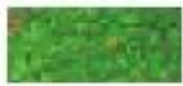

Range land

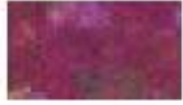

\section{Transitional area}

\section{Fig. 2 Scanned Satellite Image of the Study Area}

Source: Satellite Image of Ekiti State, Nigeria. Sheet 244N/W (Landsat MSS), 2003

Both physiographic and standard satellite image of Landsat MSS were manually interpreted and then scanned for computer assisted analysis (see Figs. 4 and 5). Equally Idris Algorithm software program) were employed for image interpretation. The manual and computer assisted image classification were done using Maximum Likelihood Classification System (see Table 1). The Maximum Likelihood Classification Scheme was quantitatively evaluated based on both the variance and correlation of the category-response patterns when classifying an unknown pixel. The computer automatically computed areas in hectares. The change dynamics for the period of study were then calculated. Field survey (Ground-truth) to identify cultural and natural features for the land use classification was later undertaken.

The 4-Quadrout Pixel Method for Ground-truth and observation was employed. This according to TERB (1997) consists of identifying along either series of latitudinal or longitudinal lines running through the specific area covered by remotely sensed spaced based data. To this end, each location was created as a point focus with an imaginary circular path 360 degree drawn at the viewing horizon as shown in Fig. 3. This circle was bisected north, south, east west into four (4) equal quadrants. The pixel is thus the area of the circle with the location (point-focus) as centre (TERB,1997)

The percentage covers each of land use type in each of the quadrants were monitored and estimated. Average values of the 4-quadrants for each land use type were computed for each pixel as follow. 

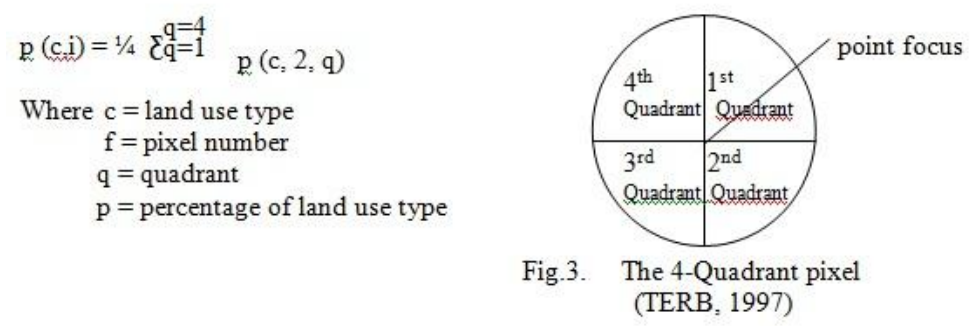

Percentage (\%) was employed in analyzing the land use type changes. This actually facilitates a clear picture of the relationship or proportion with component. In addition, 'The Mann -Whitney U-test is also used to resolve the hypothesis

Table 1 : Area Distribution of Land use

\begin{tabular}{|c|c|c|c|}
\hline $\mathrm{S} / \mathrm{N}$ & Major Land use classes & Manual classification & Digital classification \\
\hline 1. & Urban or Built-up land & $\begin{array}{l}11 \text { Residential } \\
12 \text { Commercial and } \\
\quad \text { Service } \\
13 \text { Transportation and } \\
\text { communication }\end{array}$ & $\begin{array}{l}\text { 11. Residential } \\
\text { 12. Commercial and } \\
\text { service } \\
13 \text { Transportation and } \\
\text { communication }\end{array}$ \\
\hline 2. & Agricultural Land & $\begin{array}{l}21 \text { Cropland } \\
22 \text { Other Agricultural } \\
\text { land }\end{array}$ & $\begin{array}{l}21 \text { Crop land } \\
22 \text { Other Agricultural land }\end{array}$ \\
\hline 3. & Range land & $\begin{array}{l}31 \text { Shrub and brush } \\
\text { range } \\
32 \text { Mixed range land }\end{array}$ & $\begin{array}{l}31 \text { Shrub and brush range } \\
\text { land } \\
32 \text { Mixed rang land }\end{array}$ \\
\hline 4 & Forest land & $\begin{array}{l}41 \text { Deciduous forest } \\
\text { land } \\
42 \text { Mixed forest land }\end{array}$ & $\begin{array}{l}41 \text { Deciduous forest land } \\
42 \text { Mixed forest land }\end{array}$ \\
\hline 5. & Water & 51Streamsand Reservoir & 51 Stream and Reservoir \\
\hline 6 & Wet land & $\begin{array}{l}61 \text { Vegetated wetland } \\
62 \text { Non-Vegetated } \\
\text { wetland }\end{array}$ & $\begin{array}{l}61 \text { Vegetated wetland } \\
62 \text { Non-vegetated } \\
\text { wetland }\end{array}$ \\
\hline 7. & Barren land & $\begin{array}{l}71 \text { Bare Exposed Rock } \\
72 \text { Transitional Areas }\end{array}$ & $\begin{array}{l}71 \text { Bare Exposed Rock } \\
72 \text { Transitional Areas }\end{array}$ \\
\hline
\end{tabular}

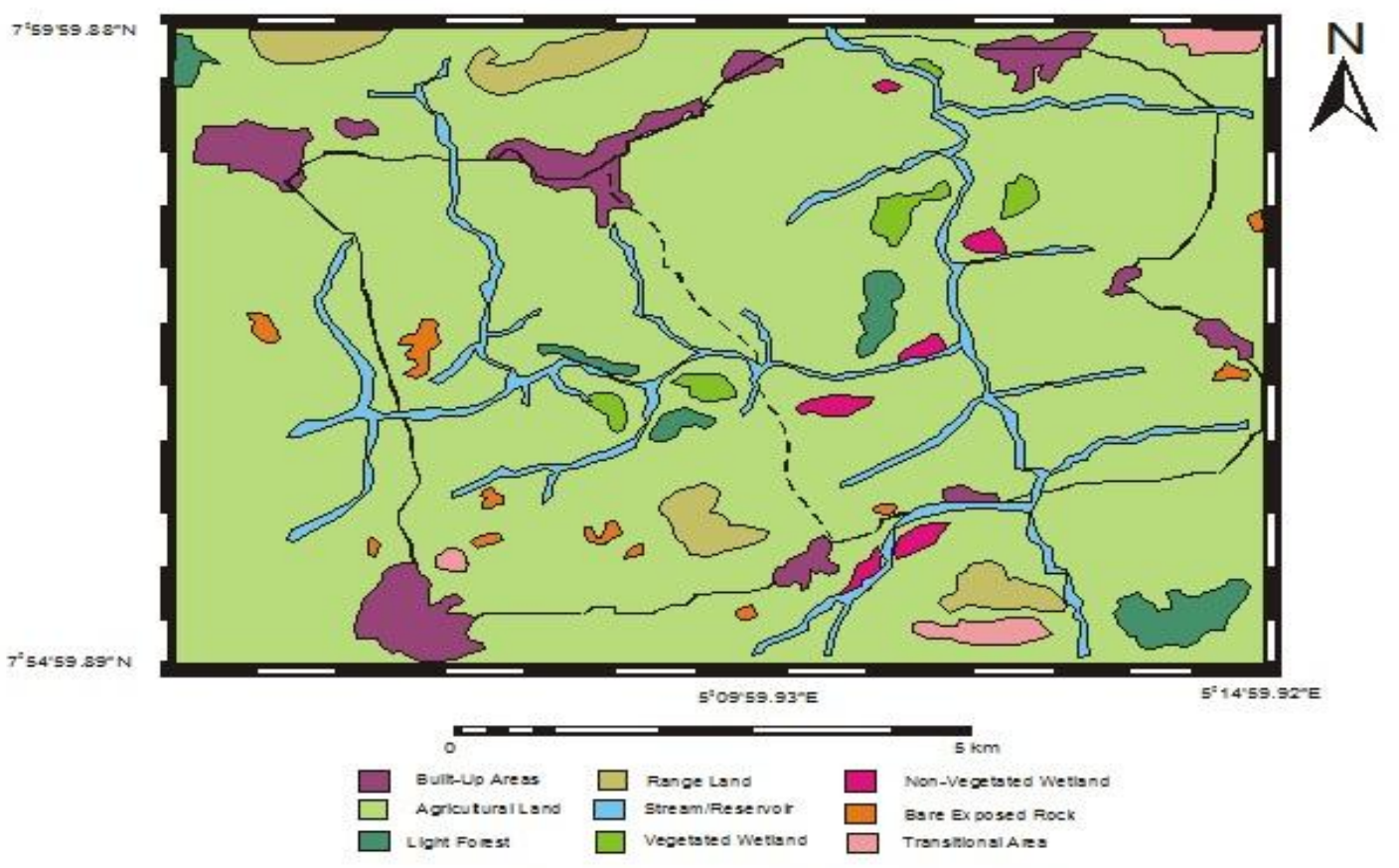

Fig. 4 Land Use Classification of the Study Area (1983). Source: Physiographic Map of Ekiti, Sheet 244 NW 


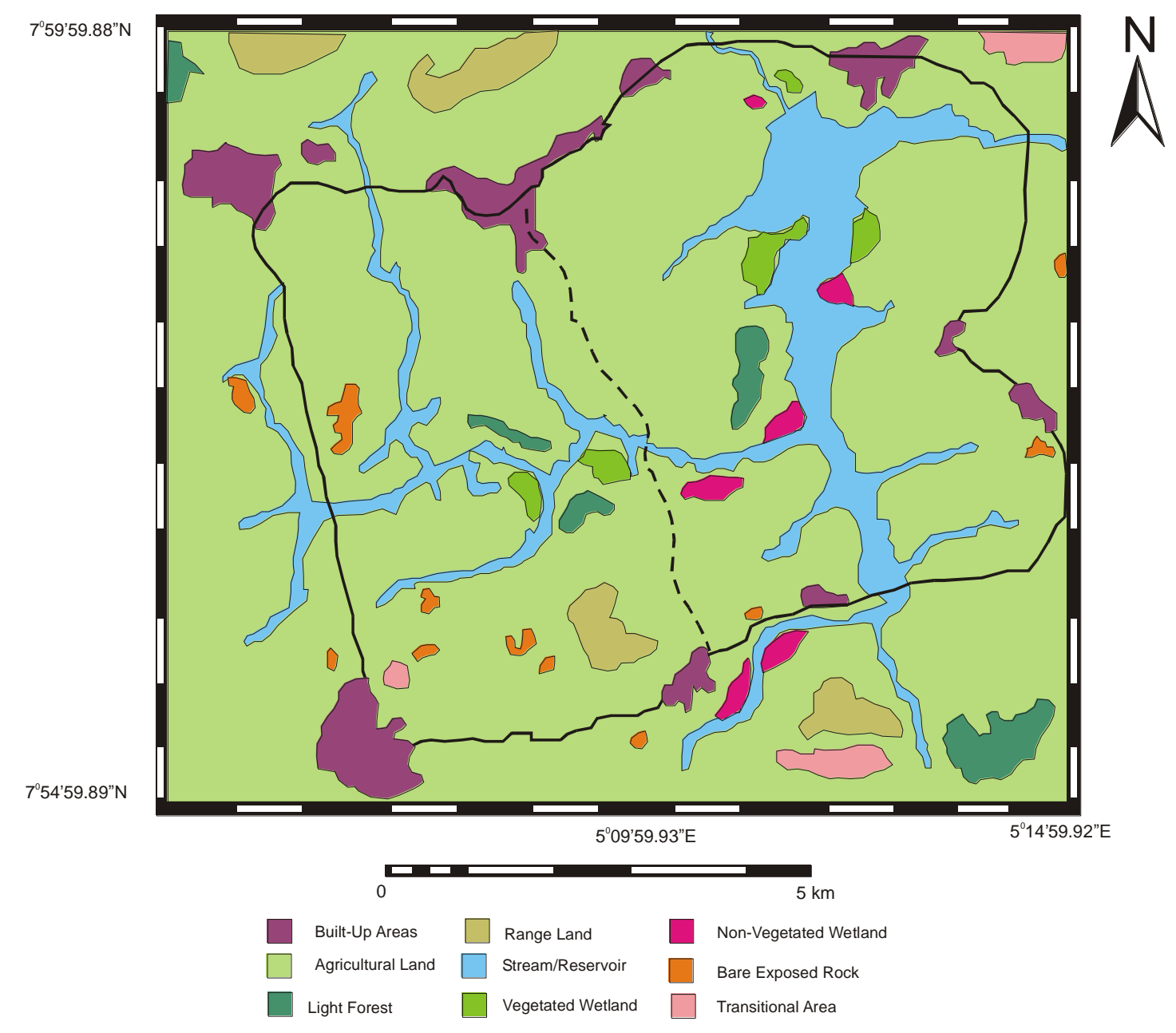

Fig. 5 Land Use Classification of the Study Area (2003)

Source: Satellite Image of Ekiti State, Nigeria. Sheet 244NW (Landsat Mss), 2003

\section{Results and Discussion}

Information on the land use changes as observed in the area are as presented in

Table 2: Area Distribution of hand use categories magnitude of change between 1983 and 2003.

\begin{tabular}{|c|c|c|c|c|c|c|}
\hline \multirow[t]{2}{*}{$\mathrm{S} / \mathrm{N}$} & \multirow[t]{2}{*}{ Landuse/Landcover categories } & \multicolumn{2}{|c|}{1973 Area } & \multicolumn{2}{|c|}{2003 Area } & \multirow{2}{*}{$\begin{array}{l}\text { Magnitude \% } \\
\text { change in } \mathrm{Ha}\end{array}$} \\
\hline & & $\mathrm{Ha}$ & $\%$ & $\mathrm{Ha}$ & $\%$ & \\
\hline 1 & Urban/Built-up land & 1091 & 4.45 & 1650 & 6.74 & 559 \\
\hline 2. & Agricultural land & 15958 & 65.16 & 12852 & 52.48 & -3106 \\
\hline 3. & Forest land & 2049 & 8.37 & 1536 & 6.27 & -513 \\
\hline 4. & Range land & 2494 & 10.18 & 2727 & 11.13 & 233 \\
\hline 5. & Streams and reservoir & 776 & 3.17 & 2778 & 11.34 & 2002 \\
\hline \multirow[t]{3}{*}{6.} & Wetland & & & & & \\
\hline & - vegetated wetland & 886 & 3.62 & 1127 & 4.60 & 241 \\
\hline & - Non vegetation wetland & 413 & 1.70 & 915 & 3.74 & 502 \\
\hline \multirow[t]{4}{*}{7.} & Barpen land & & & & & \\
\hline & -Bare exposed rock & 82 & 0.35 & 95 & 0.39 & 13 \\
\hline & - Transitional Area & 742 & 3.03 & 811 & 3.31 & 69 \\
\hline & Ground Total & 24491 & 100 & 24491 & 100 & \\
\hline
\end{tabular}

It is observed from Table 2 that certain changes have occurred over time between 1983 and 2003 in the land use distribution of the study area. (1983 represents pre-down period). The agricultural land witnesses a reduction of size from 15,958 hectares to 12,852 lectures which is about 3106 lectures lesser than the former 
size. Later bodies witnessed a considerable increase of size of about 2002 lectures over the precious size of 776 lectures. In other words, streams and reservoir which formed 3.17\% of the total area of pre-dam have now increased to about $11.34 \%$ of the total area at post-dam period. Other area rangeland, wetland and barren lands, while forestland in addition to the agriculture land also witness a decrease in size.

In addition to the percentage analysis of the changes, the Mann Whitney U-test is equally employed to test in hypothesis. The result reveals that the calculated $U$ value of 29 is more than the table critical $U$ value of 17 at 0.05 . Thus, Ho cannot be rejected. By implication therefore, there is no significant difference between predam and post-dam construction in land use distribution in the study area. In other words, the observed variation in land use distribution at pre-dam and post-dam period must have occurred by chance except in the area of agricultural land and the area cover by the reservoir.

\section{Conclusion}

This study has demonstrated that remote sensing data in good for carrying out land use auditing in dam catchments basin environment. It has equally provided a mapping scheme that could served as a springboard for generating data for subsequent land use monitoring in the study area.

This study equally established that no remote sensing studies can be successfully and effectively carried out without thorough ground-truth exercise. This is necessary to avoid confusion.

\section{Recommendations}

A thorough environmental survey has to be conducted in the area using diverse method of investigation. Attention should be given to historical data for example, land use, foresting, climate, and biomass stock among others. This will actually provide a comprehensive data base for effective monitoring of the environment.

Data should be quantified based on scientific methodology rather than using surrogate data. Remote sensing and GIS technology is on the cutting edge of technology and is capable of supporting any research work.

\section{References}

[1.] Adams, W.M. (1975) The Downstream Impacts of Dams Construction, Nigeria Transactions. Institute of British Geographers New Series. No 10 Pg. $290-307$.

[2.] Adeniyi, P.O. (1988) Using Remote Sensing to Evaluate the Impact of Dam Construction in North Western Nigeria: A paper presented at the $22^{\text {nd }}$ International Symposium on Remote Sensing Coted'vaire.

[3.] Adeniyi, P.O. and A. Omojola (1999) Land use/ Land cover Change Evaluation I Sokoto-Rima Basin of Northwest Nigeria Based on Archival Remote Sensing and GIS Techniques. in Adeniyi, P.O. (ed) Geoinformation Technology Applications for Resource and Environment in Africa. African Association of Remote Sensing of the Environment. Wura-Kay Prints, pp 143-172.

[4.] Charles, N. and I. I. Y. Mallo (2007) Application of Remote Sensing and GIS Technics in Mapping Oil Spill Affected Areas in Ogoni Land, Nigeria, Niger Delta. In Mamman, A. B, Chup C. D. and S. A. Mashi. (ed). Urbanization Resource Exploitation and Environmental Stability in Nigeria. Pgs. $51-61$.

[5.] Downman, I. J., (1981) Topographic Mapping using space Imagery. Mission Requirement Reports Prepared for European space Agency.

[6.] Epp, H. Cane, M.A. and C.E. Bussing (1983) Application of Remote Sensing in Earth Resources Monitoring in Kenya. T C Journal. 18/982 - 2, $148-153$.

[7.] Estees, J. E. Jensen, J. R. and D. S. Simoneth (1980) Impacts of Remote Sensing on US. Geography. Remote Sensing of Environment. $10,43-50$.

[8.] Franklin. S. and P.H.T. Hienaux (1993) Reflectance of Vegetation and Soil in Chihuahuan Desert Plant Communities from Ground Radiometry using SPOT Wavebands. Remote Sensing Environment. 46, 291 - 304.

[9.] Garbrecht, C. J. (1983) An Environmental Evaluation System for Water Resource Planning. Water Resource Research. 9, $523-535$.

[10.] Igbokwe, J.Z. (1996) Mapping from Satellite Remote Sensing. Enugu, EL' Demark Publishers.

[11.] Larson, R.A and L. Stromquist (1994) Practical Approaches to Applied Remote Sensing as illustrated by the SAMOZ Project in Mozambique UNGI report No. 86. Uppsala University Rnst. of Earth Sciences. Uppsala.

[12.] Lillesand, T.M. and R.W. Kiefer (1987) Remote Sensing and Image Interpretation New York. John Wiley and Sons.

[13.] Lo, C.P. (1987) Applied Remote Sensing. University of Georgia.

[14.] Odihi, J.O. (1991) Downstream problems of Dammed Rivers in Nigeria. A case study of Water Resources Development A paper presented at Nigeria Geography Association Conference.

[15.] Okhimamhe, A.O. (1993) Assessment of Environmental Impact of Dam Construction in Nigeria. A case study of Tiga Dam in Kano State. Unpublished Master Degree Dissertation. F.U.T. Minna.

[16.] Ononiwu, W.U. (1987) Environmental Impact Assessment of Tim Mining zone within Barkin Ladi Area of Plateau State using Landsat. National Water Resources Institutes Bulletin. 5.

[17.] Ononiwu, W.U. (1989) Extraction of Topographic Information from SPOT Imagery by using DSRI and analysis photogram metric Instrument and sand Image Processor. Unpublished M.Sc. Dissertation. University of London.

[18.] Rango, A. (1983) Lecture on Watershed characterization using Remote Sensing. $5^{\text {th }}$ UN Training Course on Application of Remote Sensing to water Resources. Rome.

[19.] Rufai, L.H. (1999) Social Consequences of Dam Construction: A Case Study of Shiroro Dam in Niger State. Unpublished B.Sc. Project University of Abuja.

[20.] TERB (1997) Ondo and Ekiti State of Nigeria: Report on Hydro-Eco Zones Mapping of Major River Catchment Basins. Akure. The Environmental Research Bureau (TERB). 